\title{
Alternative proton binding mode in ATP synthases
}

\section{Journal Article}

Author(s):

von Ballmoos, Christoph

Publication date:

2007-12

Permanent link:

https://doi.org/10.3929/ethz-b-000058155

Rights / license:

In Copyright - Non-Commercial Use Permitted

Originally published in:

Journal of Bioenergetics and Biomembranes 39(5-6), https://doi.org/10.1007/s10863-007-9110-1 


\title{
Alternative proton binding mode in ATP synthases
}

\author{
Christoph von Ballmoos
}

Published online: 27 October 2007

(C) Springer Science + Business Media, LLC 2007

\begin{abstract}
ATP synthases are rotary engines which use the energy stored in a transmembrane electrochemical gradient of protons or sodium ions to catalyze the formation of ATP by ADP and inorganic phosphate. Current models predict that protonation/deprotonation of specific amino acids of the rotating c-ring, extracting protons from one side and delivering them to the other side of the membrane, are at the core of the proton translocation mechanism of these enzymes. In this minireview, an alternative proton binding mechanism is presented, considering hydronium ion coordination as proposed earlier. Biochemical data and structural considerations provide evidence for two different proton binding modes in the c-ring of $\mathrm{H}^{+}$-translocating ATP synthases. Recent investigations in several other proton translocating membrane proteins suggest, that hydronium ion coordination by proteins might display a general principle which was so far underestimated in ATP synthases.
\end{abstract}

Keywords ATP synthase - DCCD · c-ring · Hydronium ion · Proton translocation

\section{Introduction}

Adenosinetriphosphate (ATP) is used as a general energy source by all living cells. The free energy released by hydrolyzing its terminal phosphoric acid anhydride bond to

C. von Ballmoos $(\square)$

Institute of Microbiology,

ETH Zürich, Wolfgang-Pauli Strasse 10,

CH-8093 Zürich, Switzerland

e-mail: ballmoos@micro.biol.ethz.ch yield ADP and phosphate is utilized to drive various energy-consuming reactions. The ubiquitous $F_{1} F_{0}$ ATP synthase produces the majority of ATP by converting the energy stored in a transmembrane electrochemical gradient of $\mathrm{H}^{+}$or $\mathrm{Na}^{+}$into mechanical rotation. While the mechanism of ATP synthesis by the F-ATPase itself is universal, diverse biological reactions are used to energize the membrane. A proton motive force derived from photosynthesis or respiration drives ATP synthesis by $\mathrm{H}^{+}$translocating ATP synthases in chloroplasts, mitochondria, and most bacteria (Boyer 1997). Additionally, some anaerobic bacteria convert the energy of a chemical decarboxylation event into an electrochemical gradient of sodium ions, which serves a $\mathrm{Na}^{+}$-translocating $\mathrm{F}_{1} \mathrm{~F}_{0}$ ATP synthase as a primary driving force (Dimroth et al. 2003, 2006; Laubinger and Dimroth 1987). Examples of such $\mathrm{Na}^{+}$-dependent ATP synthases are the closely related enzymes from Propionigenium modestum and Ilyobacter tartaricus. Despite their different coupling ions, both classes of $\mathrm{F}_{1} \mathrm{~F}_{0}$ ATP synthases are phylogenetically related and share many common structural and functional features.

All ATP synthases are composed of two rotary motors, the membrane embedded $F_{0}$ motor (subunits $a_{2} c_{10-15}$ ) which translocates the coupling ions and the extrinsic $F_{1}$ motor (subunit $\alpha_{3} \beta_{3} \gamma \varepsilon \delta$ ), which synthesizes the ATP (Fig. 1a). The two motors are connected by a central (subunits $\gamma \varepsilon$ ) and a peripheral stalk (subunits $a_{2} \delta$ ) to exchange energy with each other (For a review, see (Capaldi and Aggeler 2002)). The $\mathrm{F}_{0}$ motor consists of a ring of $\mathrm{c}$ subunits which is abutted laterally by the a subunit and a dimer of $b$ subunits. A major difference between the $\mathrm{H}^{+}$- and $\mathrm{Na}^{+}$-dependent enzyme is the chemical nature of the binding sites on the c-ring, which shuttle the ions between two pathways leading to either side of the membrane (for a review, see Dimroth et al. 2006). In $\mathrm{H}^{+}$-translocating ATP 


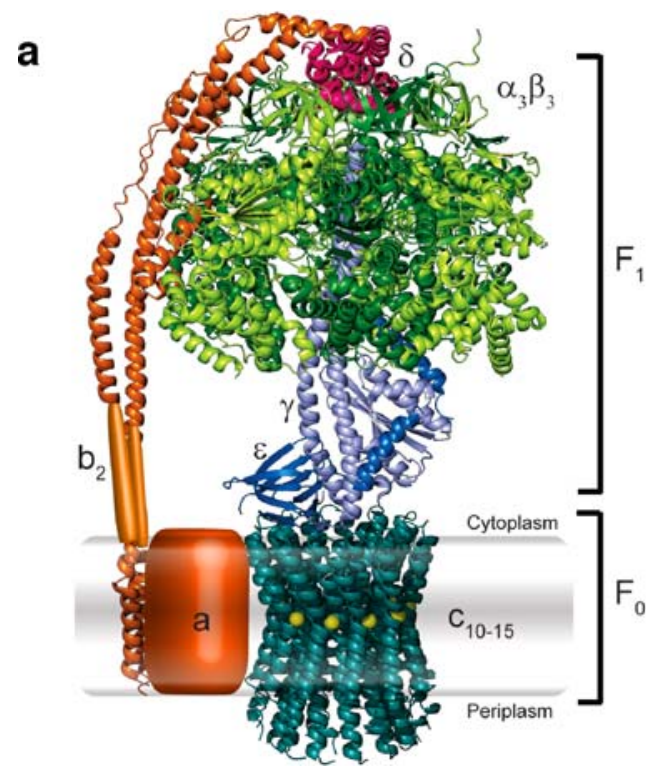

Fig. 1 a Subunit organization and secondary structure elements of the $\mathrm{F}_{1} \mathrm{~F}_{0}$ ATP synthase embedded in a membrane bilayer. The structures of individual subcomplexes were taken from RCSB Protein Data Base and assembled by eye according to biochemical data. The structures used were from the c-ring of I. tartaricus (1CYE), the $\mathrm{F}_{1}$ organization of $E$. coli $(1 \mathrm{JNV})$, the $\delta$ subunit of $E$. coli $(2 \mathrm{~A} 7 \mathrm{U})$, the peripheral stalk from bovine mitochondria (2CLY), and the membranous part of

synthases, a conserved acidic residue is thought to be sufficient for proton binding, whereas at least three residues are involved in ion binding in the $\mathrm{Na}^{+}$-translocating counterparts (Kaim et al. 1997). The view of $\mathrm{Na}^{+}$coordination by multiple residues has recently been confirmed by the high resolution structures of the c-ring of the $I$. tartaricus F-ATPase (Meier et al. 2005) and the K-ring of the Enterococcus hirae V-ATPase (Murata et al. 2005).

\section{$\mathrm{Na}^{+}$-binding by the I. tartaricus c-ring}

In the crystal structure, the I. tartaricus c-ring is composed of eleven c-monomers (Meier et al. 2005). Each monomer is folded as a helical hairpin with the loop at the cytoplasmic side and the termini at the periplasmic side. The structure shows a cylindrical, hourglass-shaped protein complex with a hydrophobic cavity in the center of the ring, presumably filled with phospholipids (Oberfeld et al. 2006).

Each of the $\mathrm{Na}^{+}$ions is bound at the interface of an Nterminal and two $\mathrm{C}$-terminal helices. The coordination sphere is formed by side chain oxygen atoms of Q32 and E65 of one subunit, and the hydroxyl oxygen atom of S66 and the carbonyl oxygen atom of V63 of the neighboring subunit (Fig. 1b). A fifth coordination site was found in the structure of the K-ring from the V-type ATPase from E. hirae (Murata et al. 2005), that could not be identified clearly in the structure of the c-ring. Interestingly, E65 acts not only as one of the four $\mathrm{Na}^{+}$-binding ligands, but also



subunit $\mathrm{b}$ of $E$. coli (1B9U). No high resolution structural data are available for subunit a and the hinge region of subunit $b$. The picture was created using Pymol (DeLano Scientific LLC). b Close-up of the $\mathrm{Na}^{+}$binding site formed by two neighboring c subunits (a and b). $\mathrm{Na}^{+}$ coordination and selected hydrogen bonds are indicated with dashed lines (see text for details)

as a recipient of three hydrogen bonds donated by the $\mathrm{NH}_{2}$ or $\mathrm{OH}$ groups of Q32, S66, and Y70.

Proton binding in $\mathrm{H}^{+}$-translocating ATP synthases

No such structural details are known for a c-ring from an $\mathrm{H}^{+}$-translocating ATP synthase, making it difficult to visualize the mode of proton binding. It is however predicted that the conserved acidic c-ring residues in the middle of the membrane shuttle between the protonated and deprotonated states to allow proton translocation across the membrane (Junge et al. 1997; Vik and Antonio 1994). A unique property of these carboxylic residues is their specific covalent interaction with the ATP synthase inhibitor dicyclohexylcarbodiimide (DCCD). In this reaction, DCCD picks up a proton from the binding site before it reacts with the carboxylate to the fragile $O$-acyl urea derivative that rearranges to the stable $N$-acyl urea derivative (Khorana 1953). Hence, the reaction of DCCD with the cring can be used to monitor the proton availability at the binding sites (Fig. 2a). We therefore monitored labeling rates of DCCD reaction with the c-ring of ATP synthases from several organisms over a broad $\mathrm{pH}$ range. We were surprised to discover two different labeling patterns and therefore distinct proton-binding sites in the ATP synthase family (von Ballmoos and Dimroth 2007). One group of enzymes, represented by the ATP synthase from Halobacterium salinarium or I. tartaricus in its $\mathrm{H}^{+}$-translocation mode 
a

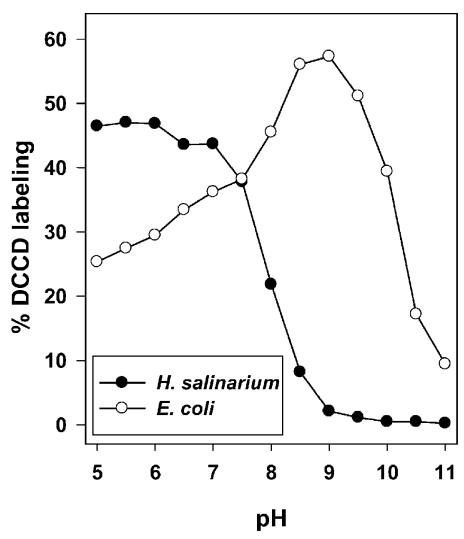

Fig. 2 Alternative proton binding mechanism in ATP synthases. a pH dependence for the modification of $\mathrm{c}$ subunit binding sites by DCCD. Depicted are representatives from each class of proton-translocating enzymes. The ATP synthase of $H$. salinarium shows the expected profile for the protonation of a carboxylate, whereas the profile of the E. coli ATP synthase might reflect the coordination of a hydronium ion. $\mathbf{b} \mathrm{pH}$ dependence for the modification of wt and mutant $\mathrm{c}$ subunit binding sites of the I. tartaricus ATP synthase by DCCD. As observed in the enzyme of $H$. salinarium, the $\mathrm{pH}$ profile reflects a protonation of the carboxylic residue in the absence of $\mathrm{Na}^{+}$ion. In the Y70F mutant, the profile is shifted to a more bell shaped one, as observed

(in the absence of $\mathrm{Na}^{+}$), showed the typical titration curve for a carbonic acid with maximum labeling rates at low $\mathrm{pH}$, half maximal labeling at around $\mathrm{pH} 7$, and no detectable labeling at $\mathrm{pH} 8$ and above. These enzymes behave exactly as predicted by the group protonation model described above. In our experiments however, the majority of the ATP synthases, including enzymes from Escherichia coli, spinach chloroplasts, and bovine mitochondria, showed instead a more bell shaped labeling characteristic with maximal labeling rates ranging from $\mathrm{pH} 7.5$ to 9 and decreasing rates at lower or higher $\mathrm{pH}$ values (Fig. 2a; von Ballmoos and Dimroth 2007). These data are not consistent with a group protonation of the acidic c-ring residues. Instead, the proton could be coordinated as a hydronium ion, as already proposed by Paul Boyer in order to strengthen the analogy of ion binding in the $\mathrm{Na}^{+}$- and $\mathrm{H}^{+}$-translocating enzymes (Boyer 1988).

\section{Alternative proton binding modes in F-ATP synthases}

Boyer hypothesized that proton and $\mathrm{Na}^{+}$ion coordination would be much more related, if the $\mathrm{H}^{+}$is coordinated together with a water molecule to form $\mathrm{H}_{3} \mathrm{O}^{+}$. He pointed out, that both hydronium ions and $\mathrm{Na}^{+}$ions can be coordinated by crown ethers. The phenomenon of related $\mathrm{H}^{+}$and $\mathrm{Na}^{+}$binding is also visible by the $\mathrm{Na}^{+} / \mathrm{H}^{+}$ exchanger monensin as revealed from its crystal structure (Lutz et al. 1971). In the free acid form, the carboxyl group is not only used to bind the proton, but also to circularize the enzyme to a crown ether like structure with
C

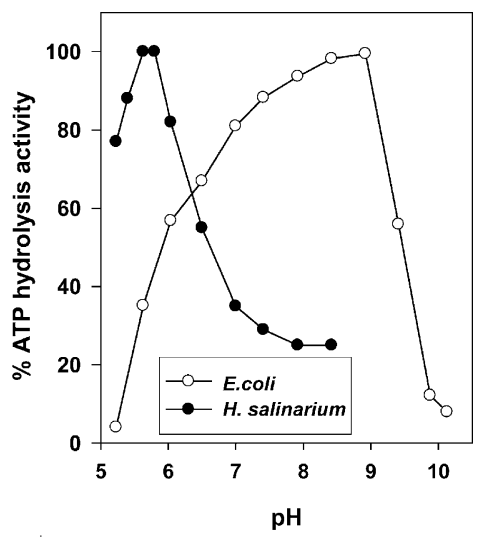

for the majority of $\mathrm{H}^{+}$- translocating enzyme (e.g. E. coli). c pH profiles of ATP hydrolysis activity from ATP synthases of different organisms. Shown are the $\mathrm{pH}$ profiles of the enzymes of $H$. salinarium and $E$. coli, representing each of the two enzyme classes. The sharp decrease of ATP hydrolysis activity above $\mathrm{pH} 6.1$ in the H. salinarium enzyme is thought to reflect the rate limiting protonation of the binding site, which is necessary during ATP hydrolysis. In contrast, the protonation of the binding site is not rate limiting in the enzyme of $E$. coli, and the $\mathrm{pH}$ profile becomes bell shaped and is shifted into the alkaline range

a bound water molecule in the middle. This conformation defines a precise hydrogen bonding scaffold, on which the positive charge of the proton is distributed. Upon $\mathrm{Na}^{+}$ binding, the water is released and the $\mathrm{Na}^{+}$becomes coordinated by several oxygens (Lutz et al. 1971).

A similar concept in ATP synthases could be validated by insights into the specific design of binding sites for $\mathrm{Na}^{+}$, $\mathrm{H}_{3} \mathrm{O}^{+}$, and $\mathrm{H}^{+}$. We rationalized that a $\mathrm{Na}^{+}$-binding site with a binding constant of about $1 \mathrm{mM}$ has to prohibit $\mathrm{H}_{3} \mathrm{O}^{+}$ binding with about six orders of magnitude higher affinity. An efficient means to prevent the binding of a hydronium ion is to donate intrinsic hydrogen bonds in the protein to the oxygen atoms of the acidic c-ring residues, as observed in the structure of the $\mathrm{Na}^{+}$-binding site of the I. tartaricus ATP synthase (Fig. 1b). With the two hydrogen bonds donated from S66 and Y70 to Oع1 and another hydrogen bond donated from Q32 to Oع2 of E65, only the latter oxygen can accept one hydrogen bond from a hydronium ion, which might prohibit efficient binding. However, if no or only one hydrogen bond donated to either of these oxygens, hydronium ion binding could be stabilized by two hydrogen bonds. The hydronium ion could donate its third hydrogen bond to a carbonyl oxygen atom of the backbone near the kink induced by breaking the helix through a proline residue (similar to V63 in I. tartaricus). In this context, it is noteworthy that no proton-translocating ATP synthase is known that has both S66 and Y70 residues. We therefore mutated critical residues of the hydrogen bonding network and determined the proton binding availability (Fig. 2b). The sigmoidal DCCD labeling profile of the wild 
type enzyme with maximal labeling at $\mathrm{pH}<6.5$ was shifted significantly in the Y70F mutant to a bell shaped profile with maximal labeling between $\mathrm{pH} 8$ and 9, and simultaneously the $\mathrm{Na}^{+}$binding affinity was severely reduced (von Ballmoos and Dimroth 2007). Thus, subtraction of a single hydrogen bond from the hydrogen bonding scaffold elicits a transition from $\mathrm{Na}^{+}$to hydronium ion binding.

\section{Effect on enzyme function}

The mode of proton binding in these distinct ATP synthases is not expected to affect the proton translocation mechanism directly, but rather to have an influence on the $\mathrm{pH}$ optimum of these enzymes. To test this, we performed ATP hydrolysis experiment in the absence of a membrane potential, which was also absent during DCCD modification experiments. Enzymes with a group protonation mechanism are predicted to have the $\mathrm{pH}$ optimum near the $\mathrm{p} K_{\mathrm{a}}$ of the acidic c-ring residues, because abundance of protons should become rate limiting at higher $\mathrm{pH}$ values as observed in the $\mathrm{H}^{+}$-translocating enzyme of $H$. salinarium and in the $\mathrm{Na}^{+}$-translocating enzyme of $P$. modestum in the $\mathrm{Na}^{+}$- and in the $\mathrm{H}^{+}$-translocating mode (Fig. 2c; von Ballmoos and Dimroth 2007). Conversely, in enzymes with a hydronium ion binding site, the $\mathrm{pH}$ optimum could be extended into the alkaline $\mathrm{pH}$ range (Fig. 2c).

Intriguingly, the DCCD labeling and ATP hydrolysis $\mathrm{pH}$ profiles of the different ATP synthases were similar (Fig. 2a-c). Such a concordance may be surprising at first glance as DCCD labeling reflects the protonation status outside the subunit a/c interface whereas rate limiting steps for ATP hydrolysis may be attributed to reactions in the interface. However, although the binding affinities of sites inside and outside the interface may deviate, they are certainly related. The similarity in the DCCD labeling and ATP hydrolysis $\mathrm{pH}$ profiles are therefore not just coincidental, but represent different approaches to probe the $\mathrm{H}^{+}$binding affinities of the binding sites (von Ballmoos and Dimroth 2007).

Hydronium ion coordination in membrane proteins

The idea of an alternative proton binding site was also postulated for $\mathrm{H}^{+}$-translocating P-type ATPases of plants, based on the crystal structure of the SERCA1a P-ATPase (Bukrinsky et al. 2001). The authors proposed a $\mathrm{H}_{3} \mathrm{O}^{+}$ binding site, comprising a conserved acidic residue and three backbone carbonyls. An alternative $\mathrm{H}^{+}$binding site involving hydronium ion coordination was also proposed for the lactose permease (Johnson et al. 2001). However, at the present resolution of the structure it was not possible to derive at an unambiguous identification of the proton translocation pathway (Abramson et al. 2003).
Several high resolution structures of membrane proteins that were solved in the last two decades revealed functional water molecules within the hydrophobic core of the proteins. This reinforced the idea that protons might migrate along water chains in a Grotthuss type of transport. Thereby, a proton is not actually transported, but rather communicated/transmitted by a propagating rearrangement of the water molecules. This type of transport is rather random in water, but might be strictly controlled in proteins. Recently, the proton binding mode has been probed in the well understood light driven $\mathrm{H}^{+}$pump bacteriorhodopsin by time resolved Fourier-transform infrared spectroscopy (trFTIR) combined with in situ $\mathrm{H}_{2}{ }^{18} \mathrm{O} /$ $\mathrm{H}_{2}{ }^{16} \mathrm{O}$ exchange experiments. The results allowed for the first time the identification of proton coordination by water molecules in a protein (Garczarek et al. 2005) and later the intimate interplay of side chains and water molecules during proton transport (Garczarek and Gerwert 2006).

The absence of a high resolution structure of a c-ring from a proton translocating ATP synthase makes it presently difficult to define the sphere for proton coordination in this enzyme class. Nonetheless, based on the $I$. tartaricus c-ring structure and the data summarized above, we propose that the hydronium ion is coordinated by both oxygen atoms of the acidic binding site residues and at least one additional oxygen atom of the backbone. In the $I$. tartaricus c-ring, the carbonyl oxygen of Val63 on the outer helix is not hydrogen bonded and acts as a $\mathrm{Na}^{+}$binding ligand due to a kink in the helices (Pro28 on the inner helix). The essential Pro64 of the E. coli c-ring might induce a similar kink and therefore accommodate for free backbone carbonyl groups.

In spite of the different ion binding modes of the ATP synthases $\left(\mathrm{Na}^{+}, \mathrm{H}^{+}, \mathrm{H}_{3} \mathrm{O}^{+}\right)$, these enzymes are closely related in using ion translocation across the membrane to induce intersubunit rotation. The individual $\mathrm{c}$ subunits share many structural elements like the helical hairpin organization and the acidic residue in the middle of the membrane providing ion binding. This strong relationship raises the idea of a common evolutionary precursor. Since functionality of the protonation dependent binding mechanism are still found in $\mathrm{Na}^{+}$dependent enzymes (Laubinger and Dimroth 1989; von Ballmoos and Dimroth 2007), the mechanism in the archaeum $H$. salinarium is likely to be the most ancient form of coupling ion binding in ATP synthases, whereas $\mathrm{Na}^{+}$und $\mathrm{H}_{3} \mathrm{O}^{+}$binding enzymes have evolved to adapt for special demands of the organism. Interestingly, an acidic $\mathrm{pH}$ optimum for ATP hydrolysis has not only been found in the enzyme of $H$. salinarium, but also in other archaebacteria. These are therefore good candidates for similar protonation-dependent enzymes (Inatomi 1986; Lübben and Schäfer 1987; Wakagi and Oshima 1985). 
Acknowledgement Work in the author's laboratory was supported by Swiss National Science Foundation.

\section{References}

Abramson J et al (2003) Science 301:610-615

Boyer PD (1988) Trends Biochem Sci 13:5-7

Boyer PD (1997) Annu Rev Biochem 66:717-749

Bukrinsky JT, Buch-Pedersen MJ, Larsen S, Palmgren MG (2001) FEBS Lett 494:6-10

Capaldi RA, Aggeler R (2002) Trends Biochem Sci 27:154-160

Dimroth P, von Ballmoos C, Meier T, Kaim G (2003) Structure (Camb) 11:1469-1473

Dimroth P, von Ballmoos C, Meier T (2006) EMBO Rep 7:276-282

Garczarek F, Gerwert K (2006) Nature 439:109-112

Garczarek F, Brown LS, Lanyi JK, Gerwert K (2005) Proc Natl Acad Sci U S A 102:3633-3638

Inatomi K (1986) J Bacteriol 167:837-841
Johnson JL, Lockheart MS, Brooker RJ (2001) J Membr Biol 181:215-224

Junge W, Lill H, Engelbrecht S (1997) Trends Biochem Sci 22:420-423

Kaim G, Wehrle F, Gerike U, Dimroth P (1997) Biochemistry 36:9185-9194

Khorana HG (1953) Chem Rev 53:145-166

Laubinger W, Dimroth P (1987) Eur J Biochem 168:475-480

Laubinger W, Dimroth P (1989) Biochemistry 28:7194-7198

Lübben M, Schäfer G (1987) Eur J Biochem 164:533-540

Lutz WK, Winkler FK, Dunitz JD (1971) Helv Chim Acta 54:11031108

Meier T, Polzer P, Diederichs K, Welte W, Dimroth P (2005) Science 308:659-662

Murata T, Yamato I, Kakinuma Y, Leslie AG, Walker JE (2005) Science 308:654-659

Oberfeld B, Brunner J, Dimroth P (2006) Biochemistry 45:1841-1851

Vik SB, Antonio BJ (1994) J Biol Chem 269:30364-30369

von Ballmoos C, Dimroth P (2007) Two distinct proton binding sites in the ATP Synthase family. Biochemistry 46(42):11800-11809

Wakagi T, Oshima T (1985) Biochim Biophys Acta 817:33-41 